\title{
Medicina interna tras la covid-19
}

\author{
Internal Medicine after Covid-19
}

\author{
Jesús Díez Manglano
}

Presidente de la Sociedad Española de Medicina interna

En los últimos dos años la coronavirus disease 19 o COVID-19 nos ha exigido un esfuerzo extraordinario en nuestro trabajo clínico habitual. Enfrentarnos a una enfermedad nueva, sin tratamiento conocido, que provoca en muchas personas cuadros muy graves y con una elevada mortalidad, ha supuesto un reto ineludible para nuestra especialidad.

Hemos desplegado nuestros recursos y hemos desarrollado los mayores esfuerzos para ayudar a nuestros pacientes. Esto ya ocurrió con la infección por el virus de la inmunodeficiencia humana, o incluso más recientemente con la amenaza de infección por el virus Ebola. Dos actitudes han distinguido la acción de los internistas: en primer lugar la disposición a trabajar de forma participativa y colaborativa con profesionales sanitarios de otros estamentos como las enfermeras, farmacéuticos, fisioterapeutas, celadores y auxiliares de enfermería, así como con los médicos de otras especialidades, y en segunda lugar el interés permanente por conocer los avances continuos en el tratamiento y diagnóstico de la enfermedad mediante la lectura y estudio de la bibliografía, la elaboración de protocolos clínicos, y por supuesto, generando nuevo conocimiento con estudios de investigación. En este sentido hay que destacar la importante contribución de los estudios derivados del registro SEMI-COVID-19, que en un tiempo record consiguió incluir miles de pacientes con la enfermedad ${ }^{1,2}$. Además los internistas han participado en comités asesores de las autoridades sanitarias y en medios de comunicación transmitiendo a la población información contrastada y veraz.

La Medicina Interna es una especialidad hospitalaria con una visión global de la persona enferma. El internista se preocupa por todas las necesidades de salud de su paciente con una aproximación rigurosa basada en los mejores conocimientos científicos, despliega las habilidades clínicas más adecuadas y utiliza los recursos sanitarios de forma racional y razonada. Sus objetivos son conseguir la mayor supervivencia de las personas, con la mejor capacidad funcional y la mejor calidad de vida posible. Todo ello contribuye a la sostenibilidad del sistema sanitario. Además los internistas siguen atendiendo a los pacientes cuando ya no existen expectativas de curación y hasta el final de su vida, priorizando la calidad de vida y el confort.

Recientemente la Sociedad Española de Medicina Interna, junto con otras sociedades científicas y asociaciones de pacientes, ha elaborado el documento "El hospital del futuro",3. Este documento reflexiona sobre los cambios que deben darse en los hospitales para adaptarse a las necesidades de la sociedad en los años venideros. Se proponen cambios organizativos con estructuras más matriciales y menos jerárquicas, y con una clara orientación hacia el paciente. Algunos de estos cambios ya están en camino o incluso ya han llegado ${ }^{5}$.

La pandemia de COVID-19 ha condicionado cambios en los profesionales y las organizaciones sanitarias. Sin embargo, la verdadera incógnita es cuántos de estos cambios van a permanecer en el futuro, y en consecuencia cómo va a evolucionar la medicina interna en los próximos años. Garantizar la continuidad con una óptima calidad asistencial durante 24 horas al día y 365 días al año y con participación y satisfacción de los pacientes, los familiares y los profesionales es el verdadero reto al que nos enfrentamos ${ }^{3}$. Para ello hay que implementar las prácticas de valor y eliminar aquellas acciones innecesarias $^{6}$. $Y$ además hay que trasladar esta actitud a la formación de los residentes y nuevos especialistas y a la formación de los estudiantes de pregrado. La pandemia también ha traído cambios en la relación médico-paciente. Se ha retrocedido en el contacto físico aumentando la impersonalidad de la atención. Sin embargo, no podemos olvidar los aspectos humanos de nuestra profesión y de nuestra especialidad. Si "curar a veces, aliviar a menudo y consolar siempre" sigue siendo nuestra realidad del día a día, no debemos olvidar que para aliviar y consolar hay que dar la mano a nuestros pacientes, mirarles a los ojos, sonreírles y mostrarles empatía y comprensión. No podemos refugiarnos tras mascarillas, guantes y pantallas más allá de lo estrictamente necesario.

La actualización permanente en nuestros conocimientos y cuidados constituyen un imperativo ético para los internistas. En los próximos años se pondrán en marcha procesos de recertificación que 


\section{El crecimiento de la población anciana y el aumento de las enfermedades crónicas hacen que el internista sea un médico cada vez más necesario en el contexto actual y que será imprescindible en el contexto sanitario del futuro}

comprueben la actualización de los conocimientos y garanticen a la población la mejor asistencia disponible. También es imprescindible la presencia de internistas en las facultades de medicina para enseñar anamnesis, exploración física, razonamiento clínico y resolución de problemas clínicos complejos. En los primeros años de este siglo XXII a investigación dirigida por especialistas en medicina interna ha tenido un desarrollo exponencial y esta tendencia va a continuar. Algunos campos de conocimiento como la multimorbilidad, la complejidad, la polifarmacia, la enfermedad sistémica, la inmunidad o los cuidados paliativos son propios de los internistas,y van a experimentar un gran desarrollo en el futuro. Se ha demostrado que los internistas diseñan, desarrollan, analizan y publican investigaciones de alta relevancia para los pacientes.

Las previsiones demográficas en España y en Europa, apuntan a un envejecimiento progresivo de la población en los próximos 30 años. El crecimiento de la población anciana y el aumento de las enfermedades crónicas hacen que el internista sea un médico cada vez más necesario en el contexto actual y que será imprescindible en el contexto sanitario del futuro. Por ello las autoridades sanitarias deberían planificar las necesidades de especialistas en medicina interna, que se van a incrementar en las próximas décadas y deberían valorar el aumento del número de plazas para formación de especialistas en medicina interna.

Todos los atributos mencionados anteriormente, actividad holística orientada al enfermo, conocimiento clínico, formación continuada, docencia, investigación, trabajo colaborativo y participativo, preocupación por la sostenibilidad del sistema sanitario y respuesta ante emergencias epidémicas definen al internista actual y al internista del futuro. Por lo tanto, elegir y ejercer la medicina interna son decisiones inteligentes hoy, y serán buenas opciones para los médicos del futuro.

\section{BIBLIOGRAFÍA}

1. Casas-Rojo JM, Antón-Santos JM, Millán-Núñez-Cortés J, Lumbreras-Rojo C, Ramos-Rincón JM, Roy-Vallejo E, et al. Características clínicas de los pacientes hospitalizados con COVID-19 en España: Resultados del registro SEMI-COVID-19. RevClinEsp. 2020; 220: 480-94.

2. Díez-Manglano J, Solís-Marquínez MN, Állvarez García A, Alcalá-Rivera N, Maderuelo Riesco I, GericóAseguinolaza M, et al; forthe SEMI-CIVD-19 network. Healthcare workers hospitalized due to COVID-19 have no higher risk of death than general population. Data from the Spanish SEMI-COVID-19 Registry. PLoS ONE. 2021; 16: e0247422.

3. Díez Manglano J, Gómez Huelgas R, Elola Somoza FJ (eds). El Hospital del Futuro Sociedad Española de Medicina Interna. Madrid, 2021.Accesible en: https://www. fesemi.org/publicaciones/el-hospital-del-futuro. Último acceso: 20 septiembre 2021.

4. Gómez-Huelgas R, Díez-Manglano J, Carretero Gómez J, Barba R, Corbella X, García-Alegría J, et al. El hospital del futuro en 10 puntos. RevClinEsp 2020; 220: 444-9.

5. García-Alegría J, Gómez-Huelgas R. Enfermedad COVID-19: el hospital del futuro ya está aquí. RevClinEsp. 2020; 220: 439-41.

6. Varela J, Zapatero A, Gómez-Huelgas R, Maestre A, Díez-Manglano J, Barba R. Por una Medicina Interna de alto valor. Sociedad Española de Medicina Interna. Madrid, 2017. Accesible en: https://www.fesemi.org/publicaciones/por-una-medicinainterna-de-alto-valor. Último acceso: 20 septiembre 2021. 